\title{
Rise in Plasma Lactate Concentrations with Psychosocial Stress: A Possible Sign of Cerebral Energy Demand
}

\author{
Britta Kubera $^{a}$ Christian Hubold $^{a}$ Saskia Otte ${ }^{a}$ \\ Ann-Sophie Lindenberg ${ }^{a} \quad$ Irena Zeiß $^{a} \quad$ Regina Krause $^{b} \quad$ Mirja Steinkamp ${ }^{a}$ \\ Johanna Klement ${ }^{a}$ Sonja Entringer ${ }^{c} \quad$ Luc Pellerin $^{d}$ Achim Peters ${ }^{a}$ \\ a Medical Clinic $1,{ }^{b}$ Clinic of Psychiatry and Psychotherapy, University of Lübeck, Lübeck, \\ Germany, ' Department of Psychiatry and Human Behavior, University of California, Irvine, \\ CA, USA, d Department of Physiology, University of Lausanne, Lausanne, Switzerland
}

\section{Key Words}

Brain-pull $\cdot$ Cerebral lactate demand $\cdot$ Social stress

\begin{abstract}
Objective: It is known that exogenous lactate given as an i.v. energy infusion is able to counteract a neuroglycopenic state that developed during psychosocial stress. It is unknown, however, whether the brain under stressful conditions can induce a rise in plasma lactate to satisfy its increased needs during stress. Since lactate is i) an alternative cerebral energy substrate to glucose and ii) its plasmatic concentration is influenced by the sympathetic nervous system, the present study aimed at investigating whether plasma lactate concentrations increase with psychosocial stress in humans. Methods: 30 healthy young men participated in two sessions (stress induced by the Trier Social Stress Test and a non-stress control session). Blood samples were frequently taken to assess plasma lactate concentrations and stress hormone profiles. Results: Plasma lactate increased 47\% during psychosocial stress (from $0.9 \pm 0.05$ to $1.4 \pm$ $0.1 \mathrm{mmol} / \mathrm{l}$; interaction time $\times$ stress intervention: $\mathrm{F}=19.7, \mathrm{p}<0.001)$. This increase in lactate concentrations during stress was associated with an increase in epinephrine $\left(R^{2}=0.221, p=\right.$ $0.02)$ and ACTH concentrations $\left(R^{2}=0.460, p<0.001\right)$. Conclusion: Plasma lactate concentrations increase during acute psychosocial stress in humans. This finding suggests the existence of a demand mechanism that functions to allocate an additional source of energy from the body towards the brain, which we refer to as 'cerebral lactate demand'.
\end{abstract}


Kubera et al.: Rise in Plasma Lactate Concentrations with Psychosocial Stress: A

Possible Sign of Cerebral Energy Demand

\section{Introduction}

Stress and eating behavior are closely related [1]. We previously proposed a cerebral supply chain model to study the interactions between central and peripheral energy metabolism [2]. The supply chain of the brain - with the central nervous system as the final consumer - describes the energy fluxes from the remote environment to the near environment through the body and finally towards the brain. The brain appears to regulate overall energy homeostasis via 'brain-pull mechanisms', i.e. by initiating allocation of energy from the body towards the brain. We have recently shown that a competent brain-pull, i.e. the brain's ability to properly demand energy from the body, functions to preserve brain mass when obese people diet [3]. By contrast, an incompetent brain-pull will lead to buildups in the cerebral supply chain culminating in obesity and type 2 diabetes [2]. In compensation for an incompetent brain-pull, the brain can initiate ingestive behavior. Under these conditions, the brain is supplied by an increased push component from the blood, which may result in weight gain in the medium or long term.

The identification of specific brain-pull mechanisms is central for the 'Selfish Brain' theory dealing with the characteristic of the human brain to cover its own, comparably high energy requirements with the utmost of priorities when regulating energy fluxes in the organism $[4,5]$.

It was shown experimentally that during acute mild mental stress the energy supply of the human brain is increased by $12 \%$ [6]. Accordingly, cerebral energy needs were enhanced during acute psychosocial stress [7]. Such stress-related augmentations suggest the existence of an underlying cerebral demand mechanism. Evidence was provided for a mechanism by which the brain under stressful conditions actively demands for extra energy from the body via cerebral insulin suppression (CIS) $[1,7]$. Cerebral activation of the sympathetic nervous system (SNS) [8, 9] and the hypothalamus-pituitary-adrenal (HPA) axis with cortisol release [10] suppresses insulin secretion from pancreatic beta cells. The insulindependent glucose uptake via glucose transporter GLUT4 into body periphery becomes limited. As a consequence, glucose is now available via insulin-independent GLUT1-transport across the blood-brain barrier $[11,12]$. Thus, a competent brain-pull is exerted by limiting the glucose transport into body periphery via CIS, and by enhancing the glucose transport into the brain. In this way, CIS can be interpreted as a brain-pull mechanism that functions to allocate energy from the body towards the brain.

Previous studies suggest that a rise in plasma lactate concentrations may be regarded as another brain-pull mechanism. First, it is known that plasma lactate is increased by activation of the SNS [13-15]. Because of its large mass and metabolic capacity, the muscle tissue is the major producer of lactate [16]. Lactate arises in the muscle tissue from the glycolytic, anaerobic breakdown of glucose. The amount of lactate produced by other tissues such as red blood cells is small [17]. Second, plasma lactate is an alternative cerebral energy substrate to glucose [18-20]. There is growing evidence that lactate even acts as the preferred energy substrate for activated neurons [21]. Lactate i.v. leads to a $17 \%$ reduction of global brain glucose uptake in PET studies, indicating that lactate may traverse the bloodbrain barrier and take over energy procurement of the brain that is usually covered by glucose [20]. Third, lactate given as an i.v. energy infusion during acute psychosocial stress is able to resolve post-stress neuroglycopenic symptoms [7]. Thus, exogenous lactate is able to compensate the cerebral energy depletion during stress.

A recent study in head-injured patients showed an increase in serum lactate as head injuries became more severe. Moreover, higher lactate levels were associated with better neurological function at hospital discharge [22]. The authors of that study concluded that the increase in serum lactate may be a mechanism by which brain function is preserved [22]. Is 
plasma lactate also increased by psychosocial stress? One previous study showed that exam stress increased lactatic acid concentrations [23]. It is unknown, however, whether a rise in plasma lactate by psychosocial stress is linked to the stress system and the cerebral need.

The objective of the present study was to examine the hypothesis that plasma lactate is increased by psychosocial stress as another brain-pull mechanism necessary to demand extra energy from the body during a mentally challenging situation. We further aimed at investigating whether peri-stress energy supplementation influences the increase in plasma lactate. Therefore, 30 healthy young men undergoing social stress were examined. Subjects were assigned to three different groups according to the energy provided during or after stress intervention (rich buffet, dextrose infusion and meager salad).

\section{Participants and Methods}

\section{Study Population}

30 healthy men aged 18.0 to 33.0 years (22.7 \pm 0.6 years) with a BMI in the normal range (19.8 to 25.0 $\left.(22.7 \pm 0.3) \mathrm{kg} / \mathrm{m}^{2}\right)$ were recruited by notice board postings. Participants met the following inclusion criteria: normal physical examination and routine laboratory tests, no physical or mental disease, no abuse of nicotine, alcohol or drugs, no nightshifts, no disturbed sleep or exceptional stress during the past 2 weeks as well as no blood donation during the past 4 weeks prior to the study. The study was approved by the local medical ethics committee of Lübeck University and was conducted in accordance with the Declaration of Helsinki. All subjects provided their fully informed and written consent before participation.

\section{Study Protocol}

Subjects were randomly assigned to three different interventional groups according to the energy provided during or after stress (high-energy groups: 'rich buffet + i.v. control (i.e. Ringer infusion)' and 'dextrose infusion + oral control (i.e. meager salad)' vs. low-energy group: 'meager salad + i.v. control'). Each subject participated in two sessions (stress intervention and non-stress control session) with an interval of 7-14 days between these two sessions. The experiments were performed in a single-blind fashion with the order of sessions balanced across subjects as in detail described elsewhere [7].

Experiments took place in a sound attenuated room with the subjects resting on a bed. One venous catheter was placed in each arm. With one cannula the infusion was applied; the other cannula was connected to a long thin tube that enabled blood sampling from an adjacent room without awareness of the subject. After taking a blood sample, the cannula was infused with a $\mathrm{NaCl}$ infusion.

After a fasting period of $2.5 \mathrm{~h}$, participants arrived at the medical research unit at 12:30. Each subject received a $250 \mathrm{ml}$ Ringer infusion (isomolar, consisting of $\mathrm{NaCl}, \mathrm{KCl}, \mathrm{CaCl}_{2}$ and water) to adjust the fluid balance and to compensate for the following blood loss. A standardized meal was offered to the subjects (potatoes, mixed vegetables, butter, chicken breast, margarine, gravy, and tomatoes with yoghurt dressing). Between 15:00 and 16:00 blood samples were taken every $15 \mathrm{~min}$. At 16:00, the experimental infusions started, lasting for $40 \mathrm{~min}$. The Ringer infusion was applied with an infusion rate of $7.5 \mathrm{ml} / \mathrm{h} /$ $\mathrm{kg}$ body mass. Dextrose infusion (500 ml dextrose infusion, $0.25 \mathrm{~mol} / \mathrm{l}$ ) was applied with an infusion rate of $5.4 \mathrm{ml} / \mathrm{h} / \mathrm{kg}$ body mass, which resulted in an efficient rise of glucose concentrations in both the stress session and the non-stress control session [7].

At 16:00, the Trier Social Stress Test (TSST) began as in detail described elsewhere [7]. Subjects were introduced to the task they would have to perform at 16:00 and then taken to another room where an audience already sat at a table and a microphone as well as video camera were installed. It was announced that a video analysis of the subject's performance would be performed. After a brief preparation period ( 3 $\min$ ), the subjects were asked to stand at the microphone and to deliver a free speech as a job applicant who was invited for a personal interview with the company manager ( $5 \mathrm{~min}$ ). If the subject finished in less than $5 \mathrm{~min}$, the jury members told the subjects that he had still some time left. If the subject stopped a second time, the audience was quiet for some seconds and then started to ask prepared questions. Afterwards, subjects had to perform a mental arithmetic task consisting of serial subtractions ( $5 \mathrm{~min}$ ). On a failure, subjects had to restart [24].

Directly after stress intervention (at 16:25 and 16:30), blood samples were taken and food was offered at 16:30. One group was offered a rich buffet, from which they could choose food for $1 \mathrm{~h}$ (for compo- 
Kubera et al.: Rise in Plasma Lactate Concentrations with Psychosocial Stress: A

Possible Sign of Cerebral Energy Demand

sition of rich buffet see [7]). Consumed food was analyzed for its amounts of energy and macronutrients by a dietician. As described previously, carbohydrate intake from a rich buffet increased from $149 \pm 13 \mathrm{~g}$ in the non-stress control session to $183 \pm 16 \mathrm{~g}$ in the stress session (main effect stress: $\mathrm{F}=6.4 ; \mathrm{p}<0.05$ ), whereas the intake of total energy (1,569 $\pm 155 \mathrm{vs} .1,383 \pm 352 \mathrm{kcal})$, protein (48 $\pm 6 \mathrm{vs} .48 \pm 4 \mathrm{~g})$ and fat (71 \pm 10 vs. $66 \pm 6 \mathrm{~g}$ ) did not differ between stress and non-stress control session (all $p>0.05$ ) [7]. The other two interventional groups (meager salad and dextrose infusion groups) received a meager salad only (mean amount of energy: $45.7 \pm 4.4 \mathrm{kcal}$, carbohydrates: $11.1 \pm 2.7 \mathrm{~g}$, fat: $0.2 \pm 0.0 \mathrm{~g}$, and protein: $1.2 \pm 0.1 \mathrm{~g}$ ). During and after meal ingestion, six blood samples were taken for lactate analysis according to the following schedule: 16:40 and between 17:00 and 18:00 every $15 \mathrm{~min}$.

The procedure in the non-stress control session was the same, except that the TSST was omitted.

\section{Laboratory Methods}

All blood samples were immediately centrifuged, and the supernatants were stored at $-60{ }^{\circ} \mathrm{C}$ until analysis. Plasma lactate concentrations were measured by an enzymatic method (Architect, Abbott, Wiesbaden, Germany, inter-assay CV 2\%, intra-assay CV <2\%). Plasma ACTH and serum cortisol were determined by immunometric assay (ACTH: intra-assay CV 6.7-9.5\%; inter-assay CV 6.1-10.0\%; cortisol: intra-assay CV 5.2-7.4\%, inter-assay CV 7.2-9.4\%). Plasma epinephrine and norepinephrine were analyzed by HPLC (Chromsystems Diagnostics by HPLC, Munich, Germany; intra-assay CV1.7-11.4\%, inter-assay CV3.7-12.7\%).

\section{Statistics}

Data analysis was performed using SPSS statistical software (SPSS 12.0, Inc., Chicago, IL, USA). Descriptive statistics were given as mean \pm SEM. ANOVA for repeated measures was used to test differences in the variation of time between stress intervention and non-stress control session. In this approach, time and stress intervention were entered as within-subject factors, interventional groups were entered as between-subject factors. Within-group differences were calculated by paired t-test. Percent increase from baseline in response to the TSST was calculated for plasma lactate and each of the stress hormones (epinephrine, norepinephrine, ACTH, and cortisol). The relationship between percent increase in lactate and percent increases in stress hormones during stress was assessed applying regression analyses. A p value (two-sided) of 0.05 was considered significant.

\section{Results}

When analyzing all interventional groups, plasma lactate concentrations increased by $47 \%$ during stress (fig. 1 ; interaction time (16:00 vs. 16:25) $\times$ stress intervention: $\mathrm{F}=19.7$, $p<0.001$; main effect time: $F=15.0, p<0.01$, main effect stress: $F=15.0, p<0.01$ ). There was no difference in the increase in plasma lactate concentrations between the interventional groups (interaction time $\times$ stress intervention $\times$ group: $F=0.2$, n.s.; main effect group: $F=0.1$; n.s.; ANOVA for repeated measures). Thus, the stress-induced increase in plasma lactate concentrations was even independent of i.v. non-lactate energy supplementation during stress (i.e. dextrose infusion). Plasma lactate concentrations decreased within approximately $15 \mathrm{~min}$ after stress exposure in the high-energy groups (rich buffet and dextrose infusion; fig. 1). By contrast, in the low-energy group (only meager salad) lactate concentrations were still elevated $1 \mathrm{~h}$ after stress exposure.

Social stress markedly induced an immediate hormonal stress response (plasma concentrations of epinephrine, norepinephrine, ACTH, and cortisol) in all three interventional groups (fig. 2). Taken all three interventional groups together, social stress increased concentrations of epinephrine by $80 \%$ (time $\times$ stress intervention: $F=12.3, p<0.01$ ), norepinephrine by $122 \%$ (time $\times$ stress intervention: $\mathrm{F}=100.2$, p < 0.001), ACTH by $200 \%$ (time $\times$ stress intervention: $\mathrm{F}=46.2$, $\mathrm{p}<0.001$ ), and cortisol by $148 \%$ (time $\times$ stress intervention: $\mathrm{F}=160.6, \mathrm{p}<0.001)$.

Percent increase in lactate concentrations during stress was significantly associated with percent increase in ACTH and epinephrine concentrations (table 1). 


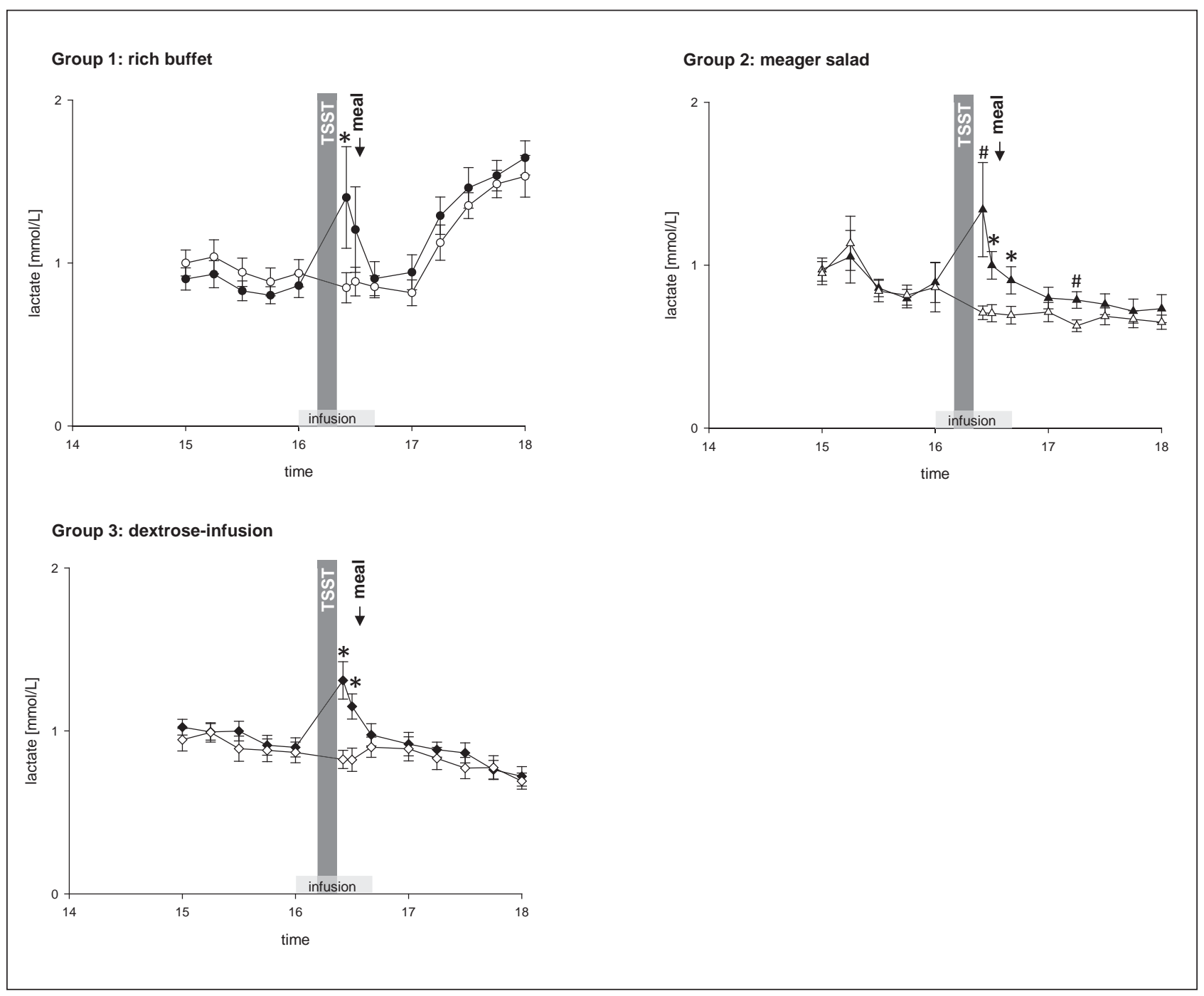

Fig. 1. Plasma lactate concentrations by time during stress intervention and non-stress control session in all three interventional groups. Values are means \pm SEM; closed circles, stress intervention and open circles, non-stress control session; ${ }^{*} \mathrm{p}<0.05$, ${ }^{\#} \mathrm{p}<0.01$, significantly different from non-stress control session by paired t-test.

Table 1. Relationship between percent increase in plasma lactate and percent increases in stress hormones during stress

\begin{tabular}{lllll}
\hline & $\mathrm{B}$ & $\mathrm{SE}$ & $\mathrm{R}^{2}$ & $\mathrm{P}$ \\
\hline Increase in plasma epinephrine, \% & 0.219 & 0.078 & 0.221 & $<0.01$ \\
Increase in plasma norepinephrine, \% & 0.170 & 0.115 & 0.072 & n.s. \\
Increase in plasma ACTH, \% & 0.153 & 0.031 & 0.460 & $<0.001$ \\
Increase in plasma cortisol, \% & 0.066 & 0.071 & 0.030 & n.s. \\
\hline
\end{tabular}

$\mathrm{B}=$ unstandardized coefficient; $\mathrm{SE}=$ standard error for B; n.s. = not significant.

aRegression analyses for 30 men 


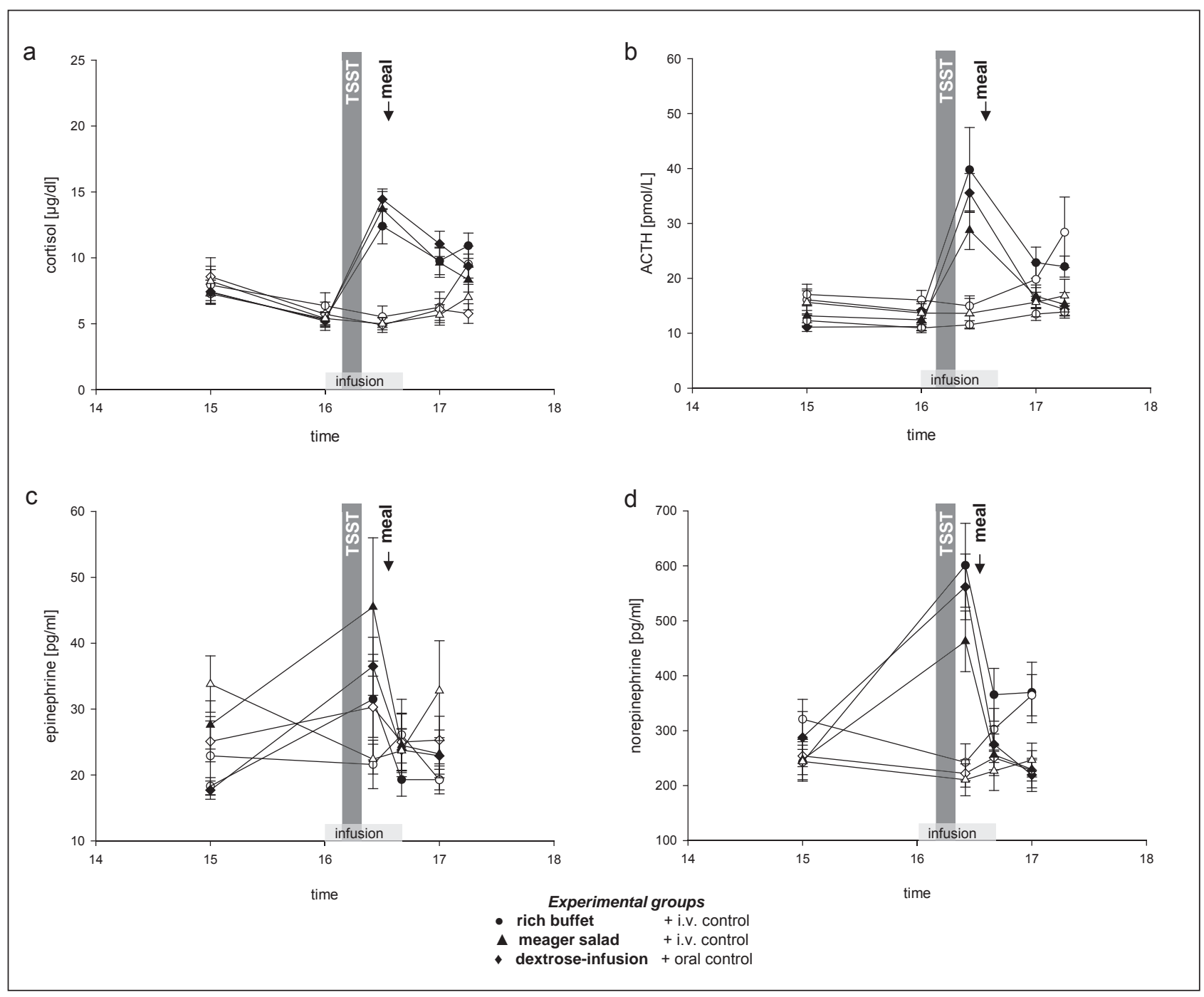

Fig. 2. Hormonal response during stress intervention and non-stress control session for a cortisol, b ACTH, c epinephrine, and $\mathbf{d}$ norepinephrine concentrations. Values are means \pm SEM; closed circles, stress intervention and open circles, non-stress control session.

\section{Discussion}

The present study shows that plasma lactate increases during acute psychosocial stress in humans. This increase in plasma lactate was linked with the hormonal stress response.

The exact origin and mechanism of lactate release cannot be identified by the present data. However, other studies suggest how psychosocial stress may have induced a rise in plasma lactate concentrations. The SNS is activated by psychosocial stress. It is known that upon activation of the SNS by the central nervous system, muscles increase their lactate production [13-15, 25]. Indeed, catecholamines increase muscle glycogenolysis and glycolysis. Such increased plasma lactate passes on to the plasma and erythrocytes [16]. Plasma lactate can be taken up by the brain via monocarboxylate transporter 1 at the bloodbrain barrier and then by neurons via the monocarboxylate transporter 2 for oxidation [26]. 
Cerebral lactate levels cannot be determined by the present data. However, previous studies suggest that increased plasma lactate reaches the cerebral circulation at considerable concentrations: First, transport of lactate across the blood-brain barrier is accelerated in proportion to its plasma concentration [27]. Second, under conditions of cerebral energy deficiency, i.e. systemic hypoglycemia, the brain takes up considerable amounts of plasma lactate [28]. Third, exogenous lactate is able to compensate the cerebral energy depletion during stress [7].

An important question addressed by the present study is whether peri-stress energy supplementation influences the duration of the stress-induced lactate increase. Energy supplementation during stress by an i.v. dextrose infusion did not dampen plasma lactate increase. In the post-stress replenishment phase, however, the duration of the increase in plasma lactate concentrations was prolonged in subjects receiving low compared to high energy. Thus, high energy supplementation is able to compensate for the cerebral energy depletion, whereas in subjects receiving low energy the increase in plasma lactate is maintained.

Integrating these results into the 'Selfish Brain' theory, it seems as if the brain demands for extra energy in order to match the enormous cerebral need during stress. Thereby the brain activates the SNS to increase lactate production in muscles. In this way, our finding of increased plasma lactate concentrations during stress may provide evidence for another brain-pull mechanism, which we refer to as 'cerebral lactate demand'.

What would happen if cerebral lactate demand fails? In a recent population-based cohort study we could show that low fasting lactate concentrations were associated with long-term weight gain and increased postprandial hunger feelings in patients with type 2 diabetes mellitus [29]. These findings suggest that an inadequate cerebral lactate demand may contribute to weight gain. What is the hallmark of an incompetent brain-pull? While a high SNS activity, which mediates cerebral lactate demand, protects against weight gain, inadequate sympatho-adrenal system activity has been shown to result in obesity. In an 18-year follow-up study, a low epinephrine response to a mental challenge was a predictor for body mass gain in men [30]. Other experimental studies confirmed that obese subjects exhibit an inadequate sympatho-adrenal system response to different stimuli such as exercise [31], cold [32], and oral glucose load [33]. Similarly, obesity-prone rats are known to exhibit an inadequate sympatho-adrenal system response to hypoglycemia [34], overfeeding [35], and chronic stress [36]. Thus, a low SNS activity is indicative for an incompetent brain-pull and also predictive for obesity.

In conclusion, the present study shows that plasma lactate is increased by psychosocial stress in humans. When discussing the findings of our study, we strictly referred to the 'Selfish Brain' theory. We found that the lactate data set presented here enlarges the theory's scope of validity. On this background, our findings suggest the existence of another brainpull mechanism during stress, which we refer to as 'cerebral lactate demand'. Cerebral lactate demand seems necessary to adequately supply the brain with an additional energy source. In this way, both brain-pull mechanisms - CIS [1] and cerebral lactate demand allocate energy in a synergistic manner to the brain in order to re-establish brain energy homeostasis.

\section{Acknowledgements}

We thank Kristin Schlichting, Kai-Uwe Duysen, Kirstin Nordhausen, and Jutta Schwanbom for carrying out the experiments and for their expert administrative and laboratory assistance.

This work was supported by a grant from the German Research Foundation (Clinical Research Group KFO-126). 
Kubera et al.: Rise in Plasma Lactate Concentrations with Psychosocial Stress: A

Possible Sign of Cerebral Energy Demand

\section{Disclosure Statement}

All authors declare that they have no conflicts of interest.

\section{References}

1 Peters A, Kubera B, Hubold C, Langemann D: The selfish brain: stress and eating behavior. Front Neurosci 2011;5:74.

2 Peters A, Langemann D: Build-ups in the supply chain of the brain: on the neuroenergetic cause of obesity and type 2 diabetes mellitus. Front Neuroenergetics 2009; doi:10.3389/neuro.14.002.2009.

- 3 Peters A, Bosy-Westphal A, Kubera B, Langemann D, Goele K, Later W, Heller M, Hubold C, Müller MJ: Why doesn't the brain lose weight, when obese people diet? Obes Facts 2011;4:151-157.

- 4 Peters A, Schweiger U, Pellerin L, Hubold C, Oltmanns KM, Conrad M, Schultes B, Born J, Fehm HL: The selfish brain: competition for energy resources. Neurosci Biobehav Rev 2004;28:143-180.

- 5 Peters A, Pellerin L, Dallman MF, Oltmanns KM, Schweiger U, Born J, Fehm HL: Causes of obesity: looking beyond the hypothalamus. Prog Neurobiol 2007;81:61-88.

6 Madsen PL, Hasselbalch SG, Hagemann LP, Olsen KS, Bulow J, Holm S, Widschiodtz G, Paulson OB, Lassen NA: Persistent resetting of the cerebral oxygen/glucose uptake ratio by brain activation: evidence obtained with the Kety-Schmidt technique. J Cereb Blood Flow Metab 1995;15:485-491.

7 Hitze B, Hubold C, van Dyken R, Schlichting K, Lehnert H, Entringer S, Peters A: How the selfish brain organizes its 'supply and demand'. Front Neuroenergetics 2010;doi: 10.3389/fnene.2010.00007.

- 8 Ahren B: Autonomic regulation of islet hormone secretion - implications for health and disease. Diabetologia 2000;43:393-410.

- 9 Woods SC, Porte D Jr: Neural control of the endocrine pancreas. Physiol Rev 1974;54:596-619.

10 Billaudel B, Sutter BC: Immediate in-vivo effect of corticosterone on glucose-induced insulin secretion in the rat. J Endocrinol 1982;95:315-320.

-11 Seaquist ER, Damberg GS, Tkac I, Gruetter R: The effect of insulin on in vivo cerebral glucose concentrations and rates of glucose transport/metabolism in humans. Diabetes 2001;50:2203-2209.

-12 Hasselbalch SG, Knudsen GM, Jakobsen J, Hageman LP, Holm S, Paulson OB: Blood-brain barrier permeability of glucose and ketone bodies during short-term starvation in humans. Am J Physiol 1995;268:E1161E1166.

-13 James JH, Wagner KR, King JK, Leffler RE, Upputuri RK, Balasubramaniam A, Friend LA, Shelly DA, Paul RJ, Fischer JE: Stimulation of both aerobic glycolysis and $\mathrm{Na}(+)-\mathrm{K}(+)-A T P a s e$ activity in skeletal muscle by epinephrine or amylin. Am J Physiol 1999;277:E176-E186.

14 Hamann JJ, Kelley KM, Gladden LB: Effect of epinephrine on net lactate uptake by contracting skeletal muscle. J Appl Physiol 2001;91:2635-2641.

15 Meyer C, Saar P, Soydan N, Eckhard M, Bretzel RG, Gerich J, Linn T: A potential important role of skeletal muscle in human counterregulation of hypoglycemia. J Clin Endocrinol Metab 2005;90:6244-6250.

16 Gladden LB: Lactate metabolism: a new paradigm for the third millennium. J Physiol 2004;558:5-30.

17 Goodwin ML, Harris JE, Hernandez A, Gladden LB: Blood lactate measurements and analysis during exercise: a guide for clinicians. J Diabetes Sci Technol 2007;1:558-569.

-18 Qu H, Haberg A, Haraldseth O, Unsgard G, Sonnewald U: (13)C MR spectroscopy study of lactate as substrate for rat brain. Dev Neurosci 2000;22:429-436.

-19 Bouzier-Sore AK, Voisin P, Canioni P, Magistretti PJ, Pellerin L: Lactate is a preferential oxidative energy substrate over glucose for neurons in culture. J Cereb Blood Flow Metab 2003;23:1298-1306.

-20 Smith D, Pernet A, Hallett WA, Bingham E, Marsden PK, Amiel SA: Lactate: a preferred fuel for human brain metabolism in vivo. J Cereb Blood Flow Metab 2003;23:658-664.

-21 Pellerin L, Magistretti PJ: Food for thought: challenging the dogmas. J Cereb Blood Flow Metab 2003;23: 1282-1286.

-22 Cureton EL, Kwan RO, Dozier KC, Sadjadi J, Pal JD, Victorino GP: A different view of lactate in trauma patients: protecting the injured brain. J Surg Res 2010;159:468-473.

-23 Hall JB, Brown DA: Plasma glucose and lactic acid alterations in response to a stressful exam. Biol Psychol 1979;8:179-188.

24 Kirschbaum C, Pirke KM, Hellhammer DH: The 'Trier Social Stress Test' - a tool for investigating psychobiological stress responses in a laboratory setting. Neuropsychobiology 1993;28:76-81.

25 Parolin ML, Chesley A, Matsos MP, Spriet LL, Jones NL, Heigenhauser GJ: Regulation of skeletal muscle glycogen phosphorylase and PDH during maximal intermittent exercise. Am J Physiol 1999;277:E890E900.

26 Pierre K, Pellerin L: Monocarboxylate transporters in the central nervous system: distribution, regulation and function. J Neurochem 2005;94:1-14.

27 Ide K, Horn A, Secher NH: Cerebral metabolic response to submaximal exercise. J Appl Physiol 1999;87: 1604-1608. 
28 Maran A, Cranston I, Lomas J, Macdonald I, Amiel SA: Protection by lactate of cerebral function during hypoglycaemia. Lancet 1994;343:16-20.

-29 van Dyken R, Hubold C, Meier S, Hitze B, Marxsen A, Oltmanns KM, Schweiger U, Lehnert H, Pellerin L, Peters A: Low plasma lactate concentrations as a biomarker of an incompetent brain pull: a risk factor for weight gain in type 2 diabetes patients. Psychoendocrinology 2010;35:1287-1293.

-30 Flaa A, Sandvik L, Kjeldsen SE, Eide IK, Rostrup M: Does sympathoadrenal activity predict changes in body fat? An 18-y follow-up study. Am J Clin Nutr 2008;87:1596-1601.

-31 Eliakim A, Nemet D, Zaldivar F, McMurray RG, Culler FL, Galassetti P, Cooper DM: Reduced exercise-associated response of the GH-IGF-I axis and catecholamines in obese children and adolescents. J Appl Physiol 2006;100:1630-1637.

-32 Nielsen B, Astrup A, Samuelsen P, Wengholt H, Christensen NJ: Effect of physical training on thermogenic responses to cold and ephedrine in obesity. Int J Obes Relat Metab Disord 1993;17:383-390.

-33 Spraul M, Anderson EA, Bogardus C, Ravussin E: Muscle sympathetic nerve activity in response to glucose ingestion. Impact of plasma insulin and body fat. Diabetes 1994;43:191-196.

34 Tkacs NC, Levin BE: Obesity-prone rats have preexisting defects in their counterregulatory response to insulin-induced hypoglycemia. Am J Physiol Regul Integr Comp Physiol 2004;287:R1110-R1115.

35 Shin AC, MohanKumar SM, Sirivelu MP, Claycombe KJ, Haywood JR, Fink GD; MohanKumar PS: Chronic exposure to a high-fat diet affects stress axis function differentially in diet-induced obese and diet-resistant rats. Int J Obes (Lond) 2010;37:1218-1226.

36 Levin BE, Richard D, Michel C, Servatius R: Differential stress responsivity in diet-induced obese and resistant rats. Am J Physiol Regul Integr Comp Physiol 2000;279:R1357-R1364. 